\title{
Single and Double Drop Impingement on a Heated Plate CFD and Experimental Investigation
}

\author{
Ruaa Basim Namaa ${ }^{1}$, Dr. Adnan A.A Rasool ${ }^{2}$ \\ ${ }^{1}$ Master. student, College of Engineering, Mustansiriyah University, Baghdad, Iraq \\ ${ }^{2}$ Professor of structural Engineering, College of Engineering, Mustansiriyah University, Baghdad, Iraq.
}

\begin{abstract}
A drop impingement on a hot surface is known as an effective way for heat removal. The present work uses a VOF (volume of fluid) model to simulate the flow behavior and temperature distribution on a $50{ }^{\circ} \mathrm{C}$ heated plate while relatively cold water drop is impinging. The temperature distribution at the impingement zone is used to examine the transient heat transfer coefficients using a single drop and double drops conditions. The spreading factor is tested in both cases. A test rig is built to verify the temperature distribution and a heat balance method is introduced to find the experimental heat coefficients on the heated. The CFD solution and its flow results gives a good agreement for single drop previous results. The results for the double drop condition show a high tendency for rebound and splash of the drop leaving the central zone without water drop coverage which way causes a burn out in case of high heat fluxes. The single drop condition show a symmetrical temperature and heat transfer coefficients distribution while the double drop impingement gives lower value of coefficients with non-uniform and unsymmetrical distribution specially at the bigger drop to plate distances. The experimental average heat coefficients gives relatively low error of only $5 \%$ in case of double drop when compared to the single drop values.
\end{abstract}

KEYWORDS: impingement, Spray cooling, Droplet impact;

\section{INTRODUCTION}

Drops impingement a promising mechanism for enhancing heat transfer. It is among all the methods of increasing convection heat transfer. it supplies a remarkably high local coefficient of heat transfer upon the surface which leads to a big amount of heat is to be removed [1]. Understanding the drop dynamics as well as the connected heat transfer in the procedure of impingement assists the better aim of such method for higher efficiency and reliability [2]. Drop impacts on liquid surfaces and solids are a significant part of a broad set of happening faced in the technical uses, like the fast spray cooling of the hot surfaces (rolls in the rolling mills for steel manufacture, turbine blades, electronic apparatuses, lasers, and semiconductor chips) $\mathrm{Al}$ and steel alloys quenching, annealing, internal combustion engines), fire suppression by sprinklers, ink-jet printing, plasma spraying, coating and spray painting, crop spraying, and incinerators [3] as well as cleaning and liquid atomization. The drop may be elliptic or spherical (owing to the oscillations) at the impact moment. A drop may impact the liquid free surface in a profound pool, upon a thin film of liquid upon a wall, or upon a desiccated surface of the solid [3]. Drop effect happens if a drop of liquid hits a surface of solid. Result of effect relies upon the surface characteristics, the drop and nearby fluid (gas which is highly common). If a drop of liquid hits a desiccated surface of solid, first it will in general spread over this surface, and after that it will retract when the effect being sufficiently active for causing the drop to expand out further than it would in general propagate owing to its static retreating angle of contact. A particular result depends on the effect, highly on the velocity, size of drop, viscosity, contact angle, surface roughness between surface and drop, and the surface tension [4]. The discrepancy in the shapes of drop for the dry horizontal surface is more obvious [5], as depicted in the figure 1.

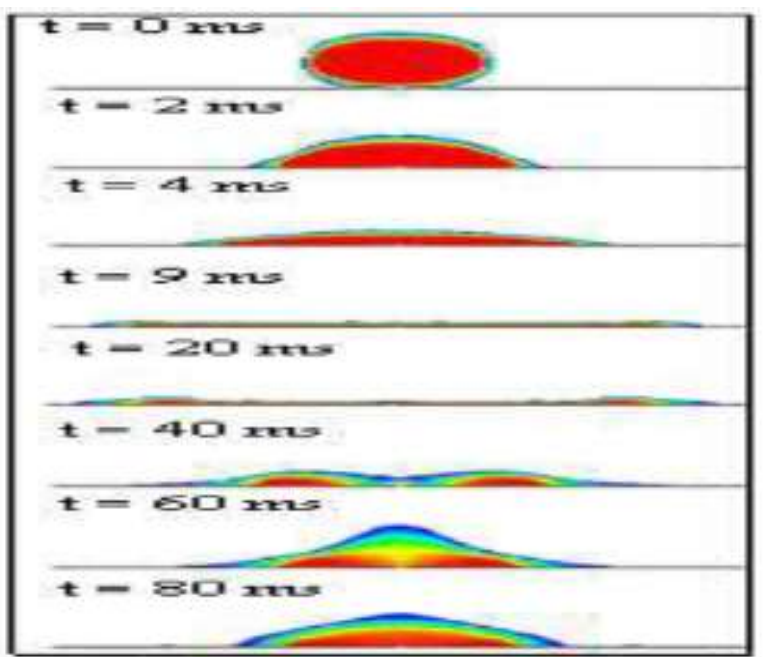

Figure 1: The development of a drop of water that impacts upon the simulation spread factors of a horizontal surface of solid.

If a drop of liquid hits an enveloped surface with a tender liquid layer that overtakes the surface coarseness height, either spreading or splashing is going to happen [3]. The 
liquid will spread on the surface, when the velocity being beneath a crucial magnitude, also a spray is going to occur and a shock wave can be generated if the speed exceeds the critical speed [6, 7]. Spraying occurs upon the thin fluid membranes in a corona form, alike to that on the desiccated hard surfaces. Below the appropriate condition, also the droplet that hits a liquid interface can show a Superhydrophobic-like Bouncing, featured via the coefficient of restitution not depending on the characteristics of the underlying liquid, the contact time and the spreading dynamics [8]. These're the noted splash secondary drops. figure 2. manifests the different stages of this impact [9].

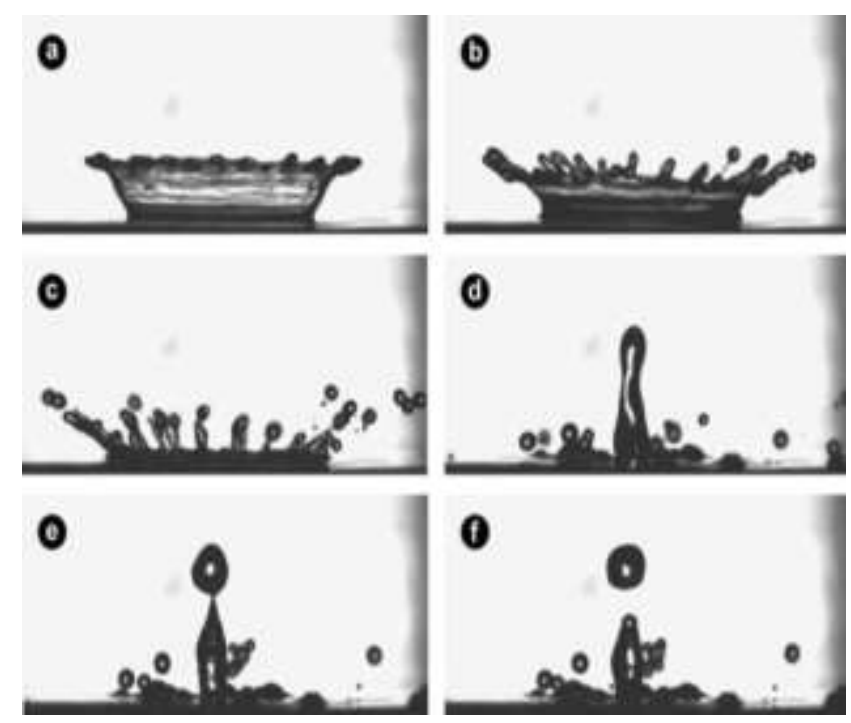

Figure 2: The impact different stages of a single drop upon a Stationary film of liquid that leads to splash:

(a) A crown-like sheet formation; (b) Jets creation;

(c) Jets disintegration and secondary droplets formation;

(d) A central jet emerging; (e) A central jet deformation; and)

(f) Disintegration

\section{MODEL DESCRIPTION AND GEOMETRY}

A two-dimensional model was created. The following is the dimensions and specifications of geometrical model. The geometrical path is air whose dimensions consist of a length that varies according to the heights, the nozzle from which one or two drops of flow forms on the surface of the plate. The dimensions of the nozzle which generates the drop is designed in a way in order to generate the required $3 \mathrm{~mm}$ diameter of the drop.This is done by trial and error. The final design of a nozzle dimensions are of length $5 \mathrm{~mm}$ and $0.5 \mathrm{~mm}$ width. The plate is made of (stainless steel), with a diameter $160 \mathrm{~mm}$ and a thickness of $0.55 \mathrm{~mm}$, as shown in figure 3 . The $(0.55 \mathrm{~mm})$ thickness of the plate is chosen so as to predict the values of heat transfer coefficients on the plate taken into account the conduction within the thin heated plate (the thin thickness ensures a condition resistance enabling temperature variations measurement). The mentioned thickness is used also on the suitable plate thickness available in the market.

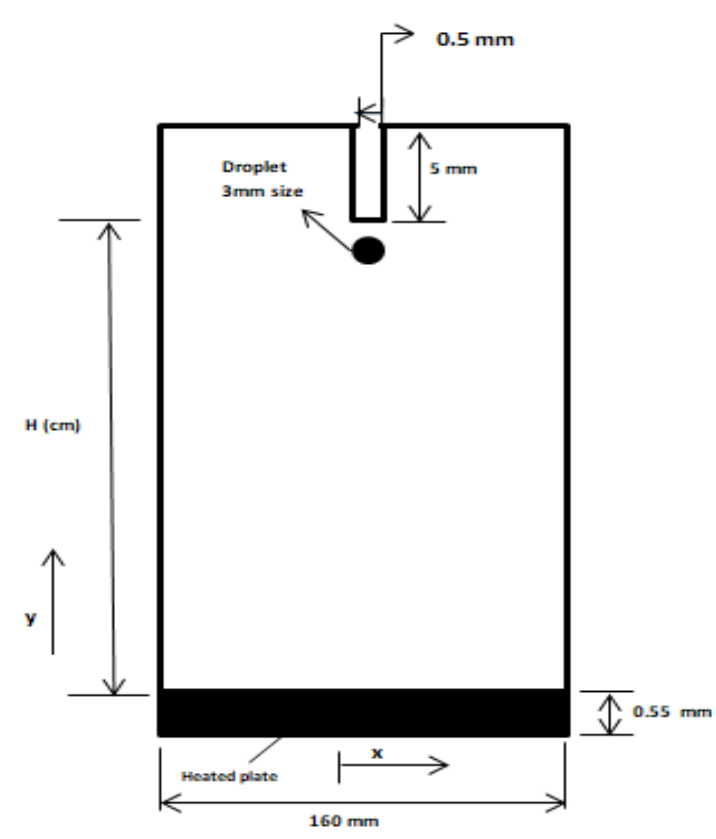

Figure 3: Numerical setup

\section{MODEL MESH}

To get a solution with a minimum error and reach the reality in the results by using two dimensional CFD model for the mesh. In the computational fluid dynamic software, the flowing area is split into too small elements, and subsequently, the governing neutralization is resolved for little elements. Better and higher accurate outcomes will be made, when using the smaller size of element in the ANSYSFluent software. Though, if a small element size is applied, the iterative computation is going to have a lengthier time. Mesh properties and methods were set founded on the commendation of ANSYS software documents for he twophase heat transfer and the flow condition study simulation and solution. The simulation of mesh includes the total element size $(0.5 \mathrm{~mm})$ and using inflation which is close to the front edge of the plate. Thus, the concentration of cells is very high, for capturing the droplet and the droplet temperature change as well as to capturing the coefficient of convection heat transfer.

\section{CFD SOLUTION SETUP AND BOUNDARY CONDITIONS}

A volume of fluid (VOF) code was used for studying the flow of fluid and the heat transfer during the droplet collision. By solving the volume fraction tracking of both the fluids through the domain and a one momentum equations set, the model of volume of fluid is able to model 2 or more immiscible fluids. In ANSYS-Fluent, the volume formulation is utilized for computing a time-dependent solution. The application of the volume of fluid model comprises free surface-flows, stratified flows, filling, the liquid motion beyond a break of dam, sloshing the jet disintegration (surface tension) prediction, the steady or the transient tracking of any liquid-gas interface, and the big bubbles motion in a liquid. 
Two phase flow is used during transient process when the droplet impinges on the heated plate and start to spread outward on the plate. This condition is covered in the ANSYS theory. Pressure-based is the appropriate solver for two phase simulation[10]. In y-direction is activated with the gravity with its values $(-9.81) \mathrm{m}^{2} / \mathrm{sec}$. For including the thermal influences into the simulation, a model of energy was activated. Implicit body force was also activating. The materials are included from the fluid (water-liquid, air) and solid (stainless-steel). Air was used as a principal phase, whereas water-liquid was used as a secondary phase. The fluid flow conditions were taken as laminar and incompressible. Heat flux applied in the bottom edge for the stainless steel plate is regulated so as to generate surface temperature of $50^{\circ} \mathrm{C}$ at the plate surface. The numerical solution requires the adjustment of flow rate through the nozzle. This adjustment is done with ability of drop rate to be within two drops per second. The single drop case is also controlled to be within this time limit. The initial temperature for the droplet is $25^{\circ} \mathrm{C}$, and the plate surface was initially at $50^{\circ} \mathrm{C}$ subjected to transient conditions. The value of the surface tension between the phases is $(0.072 \mathrm{~N} / \mathrm{m})$. A $(1 \times 10$ 4) step of time is established for insuring Courant no. at the interface of phases to be lower than one. A coupled system technique is utilized for the pressure based-solver for calculating the volume fractions at every step of time.

\section{MATHEMATICAL MODEL}

For setting the water droplet motion during the impact on the plate, the momentum, energy and mass continuity governing equations are given below [11-13].

\subsection{Continuity equation}

For getting the volume fraction conservation equations, based on the VOF model physical principles, the continuity equation is represented as follows:

$$
\nabla \cdot(\rho V)=-\frac{\partial \rho}{\partial t}
$$

Equation (1) solution for the single phase (gas) volume fraction is utilized to track the boundary edges between the phases. Therefore, the continuity equation for the liquid phase can be written as:

$$
\nabla \cdot(\propto \mathrm{\iota} \rho \mathrm{l} V)=-\frac{\partial}{\partial t}(\propto \mathrm{\imath} \rho \mathrm{l})
$$

The equation of continuity mentioned above could be the volume fraction equation and it won't be resolved for the first stage of gas, since the volume fraction first stage being studied utilizing the next term as:

$$
\sum_{g=1}^{n} \propto_{g}=1
$$

If the cell isn't completely filled by the principal phase ( $\mathrm{g}$ ) or secondary phase (L), a mixture of phases ( $g$ and $L$ ) will occur.
Thus, the density of mixture as the mean density volume fraction will be calculated as follows:

$$
\rho=\propto_{\mathrm{l}} \rho_{\mathrm{l}}+\left(1-\propto_{\mathrm{l}}\right) \rho_{g}
$$

\subsection{Momentum equation}

For the type analysis of the volume of fluid, the acting forces in fluid were believed to be surface tension, friction, pressure, and gravitational. The Continuum Surface Force (CSF) variable has been supplemented to the threedimensional momentum formula, to locate the influence of surface tension alongside the two-stage interface.

$$
\mathrm{F}_{\mathrm{CSF}}=2 \sigma \frac{\alpha_{\mathrm{l}} \rho_{\mathrm{l}} c_{g} \nabla \alpha_{g}+\alpha_{g} \rho_{g} c_{\mathrm{l}} \nabla \alpha_{\mathrm{l}}}{\rho_{\mathrm{l}}+\rho_{g}}
$$

Via regarding the FCSF forces into the model of volume of fluid, the equation of momentum is written as

$$
\begin{aligned}
& \frac{\partial}{\partial \mathrm{t}}(\rho V)+\nabla \cdot\left(\rho V V^{T}\right)=\rho g-\nabla p+\nabla \cdot\left[\mu\left(\nabla V+(\nabla V)^{T}\right)-\right. \\
& \left.\frac{2}{3} \mu(\nabla \cdot V)^{I}\right]+F_{C S F}
\end{aligned}
$$

The momentum equation will be dependent upon the volume fraction $(\alpha)$ of stages in the physical characteristics account, like viscosity and density. The dynamic viscosity $(\mu)$ is computed as:

$$
\mu=\propto_{\iota} \mu_{\iota}+\left(1-\propto_{\iota}\right) \mu_{g}
$$

\subsection{Equation of energy}

For the model of the volume of fluid, the equation of energy possesses this form:

$\frac{\partial}{\partial t}(\rho E)+\nabla \cdot(\rho E V)=\nabla \cdot(K \nabla T)+\nabla(p V)$

The model of the volume regards the mass averaged computation for the energy (E) and the parameter of temperature, whereas to determine the corresponding thermal conductivity $(\mathrm{k})$, the following relation is used:

$$
\begin{aligned}
& \mathrm{k}=\propto \mathrm{l} \mathrm{kl}+\left(1-\propto_{\mathrm{l}}\right) \mathrm{k}_{\mathrm{g}} \\
& \mathrm{E}=\frac{\propto_{\mathrm{l}} \rho_{\mathrm{l}} \mathrm{E}_{\mathrm{l}}+\alpha_{\mathrm{g}} \rho_{\mathrm{g}} \mathrm{E}_{\mathrm{g}}}{\propto_{\mathrm{l}} \rho_{\mathrm{l}}+\alpha_{\mathrm{g}} \rho_{\mathrm{g}}}
\end{aligned}
$$

Where, $E_{g}$ and $E_{\mathrm{l}}$ being determined at the specific heat $\mathrm{C}_{\mathrm{g}}$ and the mass averaged temperature of every phase, as given via the state formula:

$$
\begin{aligned}
& \mathrm{E}_{\mathrm{\iota}}=\mathrm{C}_{\mathrm{\imath}} \mathrm{T} \\
& E_{g}=C_{g} T
\end{aligned}
$$

\section{EXPERIMENTAL WORK}

The details of the experimental test platform and its procedure are presented to find the transient temperature distributions on the surface of the plate after one and two drops collide on the surface of the plate and to predict the heat transfer coefficients during drop impingement process. The experimental outcomes are applied to support the theoretical analysis and results of findings for the heated plate surface. To ensure the experimental accuracy of the measuring devices, the instruments were calibrated. So as to get more 
accuracy during measuring and test processes. Figure(4) depicts the schematic diagram of the main test apparatus. Parts of the tester consist of a drop injection system (single drop and doubles drops). It consists of (the base that carries the heated plate, iron rod catcher and head of the catcher, glass tube, water injection delivery, valve with electronic gate, control timer with an operating point), power supply and voltage regulator. This rig is designed and fabricated for measuring the temperature transient variations for the heated plate at the zone at which the drop of relatively lower temperature impact the plate. The water drop injection system is designed to ensure the drop injection at certain time step as single and double drop at time interval of 0.5 seconds for the double drop case.

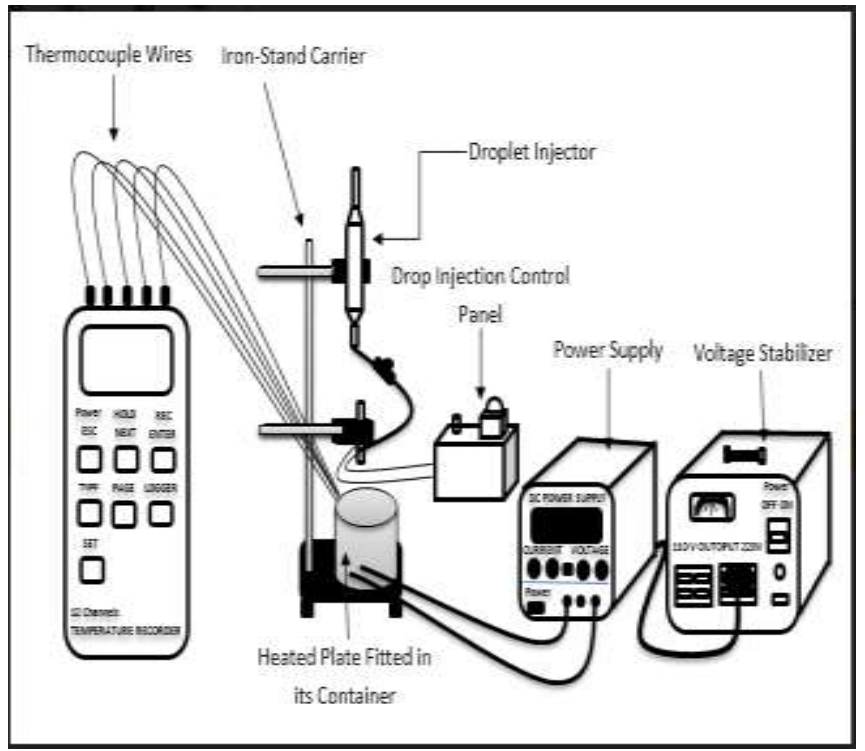

Figure 4: The schematic diagram of the used test rig

\section{Drop injection system (single drop and double drops):}

It consists of the following parts

\section{- The base that carries the heated plate}

It consists of the base, on which the iron rod is fixed, the plate is placed on the base, and the heated plate is made of stainless steel with a diameter of $(160 \mathrm{~mm})$ and a thickness of a $0.55 \mathrm{~mm}$. The $(0.55 \mathrm{~mm})$ thickness of the plate is chosen so as to ensure the presence of temperature variation during drop impact on the heated plate from which the values of the heat transfer coefficient can be predicated taking into account conduction within the thin heated plate. The plate is heated to a temperature of $50{ }^{\circ} \mathrm{C}$ by means of a heater that was constructed in the form of wires in an annular form that covers the entire area of the plate at the lower side of the plate. The power is supplied to the heater wire using a DC power supply with 30 volt and 3 Amperes. The voltage supplied is regulated through an electric stabilizer 1000 Watt in capacity. The heated plate and the aluminium plate underneath it is well insulated by glass wool which is an insulating substance made from fibres of glass sorted using a binder into a texture comparable to wool from inside and PVC (Plastic is compressed) from outside to prevent heat loss to the surroundings. At the bottom of the stainless steel plate is placed a plate made of aluminium alloy $(\mathrm{Al}=78 \% \mathrm{~K}=177$ $\mathrm{W} / \mathrm{m} . \mathrm{k}$ ) with a thickness of $2 \mathrm{~mm}$ and a diameter of $160 \mathrm{~mm}$ because aluminium is a good conductor of heat to ensure uniform heat flux distribution from the wire heater to the aluminium thick plate and then to the stainless steel thin plate. Between the two plates, a substance was placed; Zinc oxide having high thermal conductivity, high stability, less thermal resistance, high reliability, and high heat transfer conductivity, with a thermal conductivity greater than (1.93 $\mathrm{W} / \mathrm{m} . \mathrm{k})$, and a thermal resistance lower than $\left(0.225^{\circ} \mathrm{C} . \mathrm{in} 2 / \mathrm{W}\right)$. This conductive material will ensure uniform heat distribution with low thermal resistance.

\section{- Glass tube}

It is a small a cylindrical glass container with a diameter of $10 \mathrm{~cm}$. A quantity of water is placed inside it with two narrow openings, the upper (for pressure balance) and the lower for the delivery of the glass tube to water injection delivery.

\section{- Water injection delivery}

A $(0.5 \mathrm{~m})$ length PVC tube contains a movable compressor valve with two ends, the first connected to the glass tube and the second connected to the valve with electronic gate.

\section{- Valve with electronic gate}

It is controlled by an electronic timer and through it the single drop and the double drops are descended through a small opening of diameter of $0.5 \mathrm{~mm}$. The opening is designed to give a drop of $3 \mathrm{~mm}$ diameter. The $3 \mathrm{~mm}$ diameter of the drop is ensured and checked using the numerical procedure for the ejection nozzle using a trial and error with different dimensions until the required one is fixed. The trial and error numerical process for ejecting a required $3 \mathrm{~mm}$ diameter drop is mentioned in chapter three, the numerical simulation.

\section{- Control timer with an operating point}

It is associated with a valve having electronic gate, which work in such a way that it acts to control the timing of drop injection to be at one second or more according to what is required by the designer.

\section{- Power Supply}

A DC power supply is used for heating the plate electrically. The specification of the power supply is a maximum DC voltage of 30 volt and 3 Amperes. PS-305D high-precision DC power supply (a highly steady Laboratory grade (DC) power supply having the automatic overload protection). The output voltage and current can be unceasingly modified. The regulation of voltage is $\leq$ $(0.01 \%+2 \mathrm{mV})$. The regulation of load is $\leq(0.01 \%+22 \mathrm{mV})$. The power supply terminals are connected to the heater wire, the rated used voltage is $16 \mathrm{v}$ and current is $1.5 \mathrm{~A}$. 


\section{Experimental Results Analysis}

For finding the coefficient of heat transfer at a certain point on which the water drop impact and neighbouring points, the following analysis is used. The analysis takes into account the conduction within the stainless steel heated plate and the variation in temperatures occurring in it during the transient time after drop impact. The point on which the drop impact will be under the effect of convection in the zone of water drop impact while the unexposed points are assumed exposed to an air of with natural convection (low value of heat transfer coefficient), hence the temperature variations are small (surface temperature is assumed constant at about $50{ }^{\circ} \mathrm{C}$ at the region that is unaffected by water drop impingement.

The practical heat transfer coefficient (h) is calculated by deriving following equations using figure 5 . The figure uses an element of the heated subjected to a heat flux $q=$ with conduction of heat being through the element in the radial direction. The heat convection is assumed at the element of the plate.

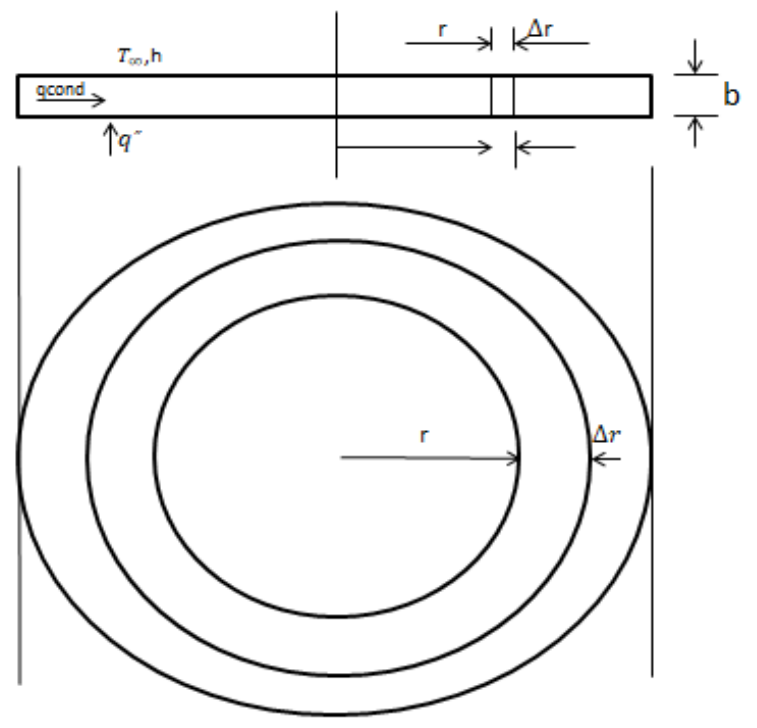

Figure 5: Representation of the energy balance on the heated plate

General Energy equation:

$\Sigma \mathrm{q}_{\text {cond }}+\Sigma \mathrm{q}_{\text {conv }}+\Sigma \mathrm{q}_{\text {generation }}=\rho v c p \frac{\partial T}{\partial t}$

$\mathrm{KA}_{\mathrm{c}} \frac{d T}{d r} \mp \mathrm{hA}_{\mathrm{s}}\left(\mathrm{T}_{\mathrm{s}}-\mathrm{T}_{\infty}\right)+\mathrm{q}^{\prime} \cdot \mathrm{A}_{\mathrm{s}}=\rho v c p \frac{\partial T}{\partial t}$

$\mathrm{K}_{\mathrm{s} . \mathrm{s}} .2 \pi \mathrm{rb} \frac{d T}{d r} \mp \mathrm{h} .2 \pi r \Delta r\left(\mathrm{~T}_{\mathrm{s}}-\mathrm{T}_{\infty}\right)+\mathrm{q}^{=} \cdot 2 \pi \mathrm{r} \Delta r=\rho c p 2 \pi r \Delta r . b \frac{\partial T}{\partial t}$

$\left[\mathrm{K}_{\mathrm{s} . \mathrm{s}} \cdot \mathrm{b} \frac{d T}{d r}-\mathrm{h} \Delta r\left(\mathrm{~T}_{\mathrm{s}}-\mathrm{T}_{\infty}\right)+\mathrm{q}^{\prime} \cdot \Delta r=\rho c p \Delta r . b \frac{\partial T}{\partial t}\right] \div b$

$\left[\mathrm{K}_{\mathrm{s} . \mathrm{s}} \frac{d T}{d r}-\frac{h}{b} \Delta r\left(\mathrm{~T}_{\mathrm{s}}-\mathrm{T}_{\infty}\right)+\frac{\mathrm{q}=}{b} \cdot \Delta r=\rho c p \Delta r \frac{\partial T}{\partial t}\right] \div \Delta r$

$\frac{\mathrm{Ks.s}}{\Delta r} \frac{d T}{d r}-\frac{h}{b}\left(\mathrm{~T}_{\mathrm{s}}-\mathrm{T}_{\infty}\right)+\frac{\mathrm{q}=}{b}=\rho c p \frac{\partial T}{\partial t}$

$\frac{h}{b}\left(\mathrm{~T}_{\mathrm{s}}-\mathrm{T}_{\infty}\right)=\frac{\text { Ks.s }}{\Delta r} \frac{d T}{d r}+\frac{\mathrm{q}=}{b}+\rho c p \frac{\partial T}{\partial t}$

$\therefore h=\frac{\left[\frac{\mathrm{Ks} . \mathrm{s}}{\Delta r} \frac{d T}{d r}+\frac{\mathrm{q}=}{b}+\rho c p \frac{\partial T}{\partial t}\right] \cdot b}{\mathrm{Ts}-\mathrm{T} \infty}$

Using the central finite different definition for $\frac{d T}{d r}$ gives,

$\frac{d T}{d r}=\frac{T_{m+1}-2 T_{m}+T_{m-1}}{\Delta r^{2}}$
And, using the explicit finite-different equation for $\frac{\partial T}{\partial t}$ gives,

$\frac{\partial T}{\partial t}=\rho c p \frac{T^{p+1}-T^{p}}{\Delta t}$

By substituting (15) and (16) into (14), then

$h=\frac{\left[\text { Ks.s } \frac{T_{m+1}-2 T_{m}+T_{m-1}}{\Delta r^{2}}+\frac{q^{q}}{b}+\rho c p \frac{T^{p+1}-T^{p}}{\Delta t}\right] \cdot b}{\text { Ts-To } \infty}$

$h=\frac{\left[\frac{\mathrm{Ks.s}}{\Delta r^{2}}\left(T_{+1}-2 T+T_{-1}\right)+\frac{q^{\prime}}{b}+\rho c p \frac{T^{p+1}-T^{p}}{\Delta t}\right] \cdot b}{\mathrm{Ts}-\mathrm{T} \infty}$

\section{RESULTS AND DISCUSSION}

Two cases are studied single drop (S.D) and double drops (D.D). The height of the nozzle that generate the drop to plate is varied in the range of $\mathrm{H}=10,20,30,40,50,60 \mathrm{~cm}$. In the mentioned height range, the flow on the plate is almost in the spreading flow mode in case of single drop case, this case is proved experimentally and numerically and agrees with previous results. In case of double drops the numerical and experimentally results show that the spreading mode occurs at only one height which is the lowest height taken i-e $\mathrm{H}=10 \mathrm{~cm}$.

The following is the results and it discussion for the two above mentioned cases, classified into numerical and experimental results.

\section{- Numerical results}

The coefficients of heat transfer (local and average)is calculated in the radial direction and also show its variation with time elapsed after impact at different heights $(\mathrm{H})$ from $(10-60) \mathrm{cm}$ and different time steps. The average values are calculated using the local values integrated over the coveraged area after impact. Maximum values are noticed and presented for each case. This is done in the numerical part only.

The Spread factor during droplet deformation is (D/Do \& $\mathrm{t} / \mathrm{t}^{*}$ ) is discussed and their relationship with collision velocities in the single drop and double drops. The spread factor represents the ratio of the diameter of coverage area after impact to the initial diameter of the drop before deformation starts. This is carried out using the numerical simulation part of drop impact

The relationship between the spread factor during droplet deformation D/Do and $t / t^{*}$ ) is shown in figure ( $6 \mathrm{~A}$ and $\mathrm{B}$ ) for the case of single drop and double drops respectively and discussed with its relationship with collision velocities in the single droplet case. It can be noticed that spread factor D/Do increases with increasing collision speed for both the single and double drops cases. In the case of double drops.

we notice that there is a difference from a single drop due to differences in the diameter of the drop diffusion and the emergence of a phenomenon of drop separation. As discussed earlier the spread factor gives an indication for the spreading of the drop during its impact on the heated surface and gives an idea of the area coverage by the water drop. In case of double drops there is a tendency for the drop to separate leading to reducing the coverage area and this may lead to a 
"Single and Double Drop Impingement on a Heated Plate CFD and Experimental Investigation"

burn out condition if the heated surface is supplied with a high heat flux.

Figure (6 A and B) shows that the spread factor initial value is 1 and its maximum value occurs at $5 \mathrm{~ms}$ time step, then re- accumulation occurs. The higher the impact velocity, the bigger is the spread factor. This is noticed for both single drop and double drops conditions with values for double drops are smaller than that for single drop

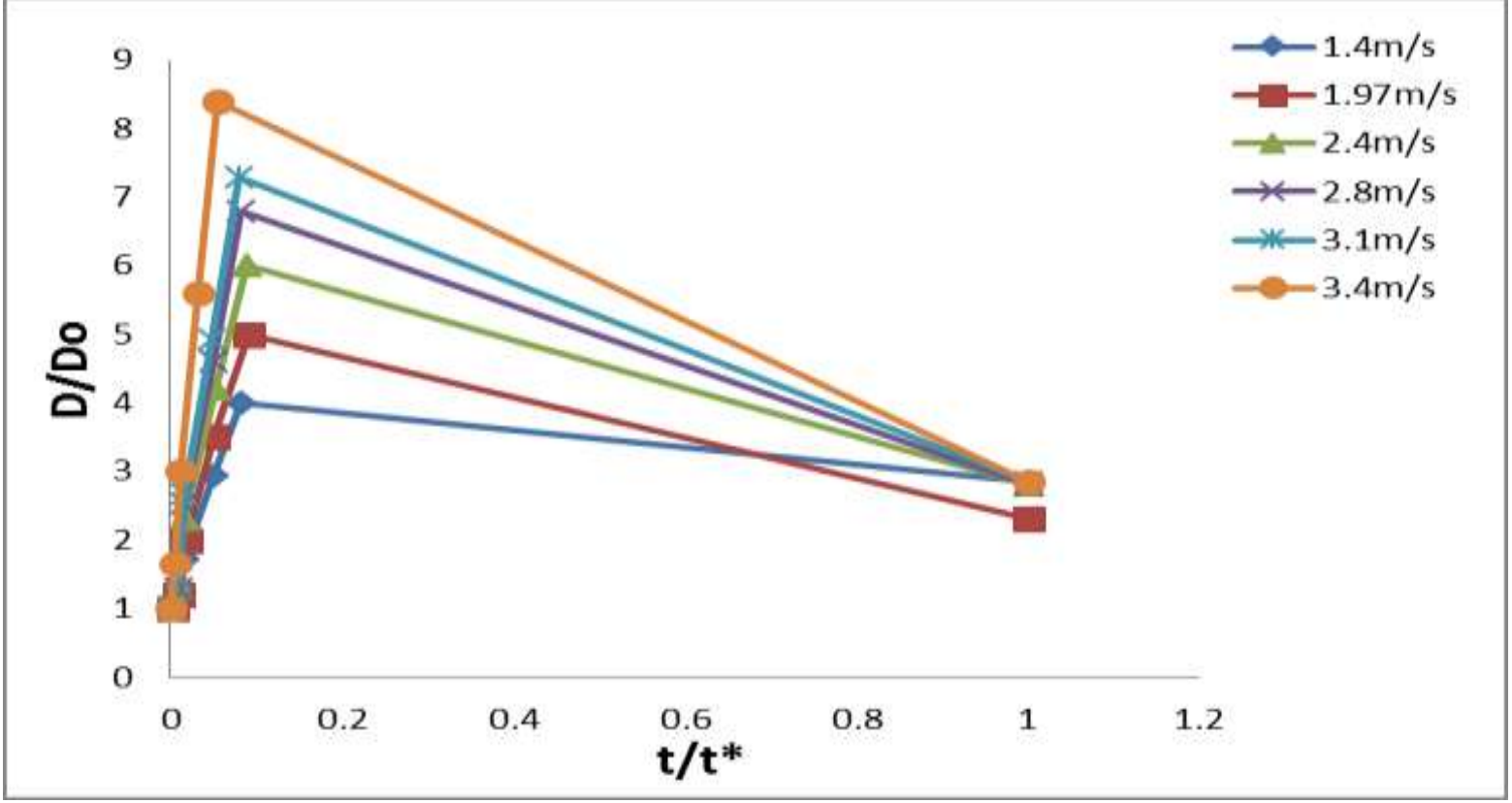

(A)

Single drops

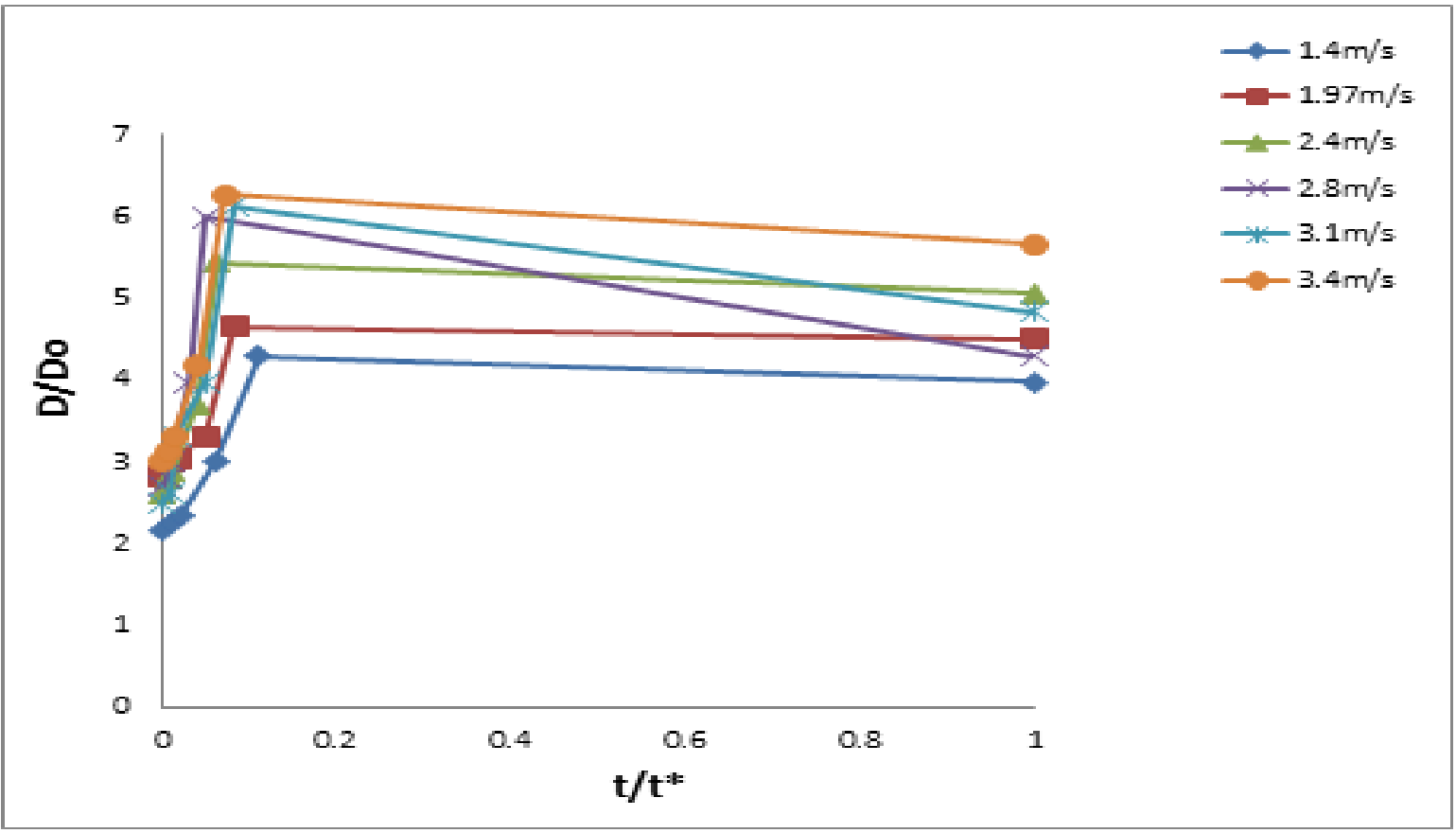

(B)

Double drops

Figure (6 A and B): The relationship between D/Do and $t / t^{*}$ in the case of single and Double drops 
The relationship between collision velocities for $(10-60 \mathrm{~cm})$ heights and the maximum heat transfer coefficient is also disused in the case of single drop and double drops as shown in figure (7 A and B)

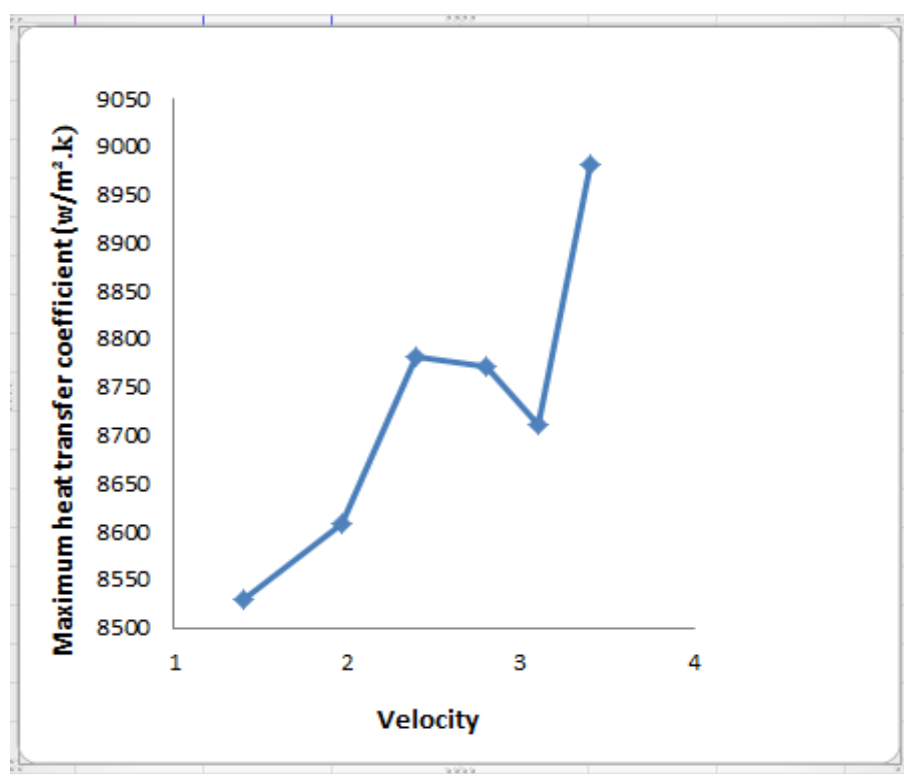

(A)

Single drop

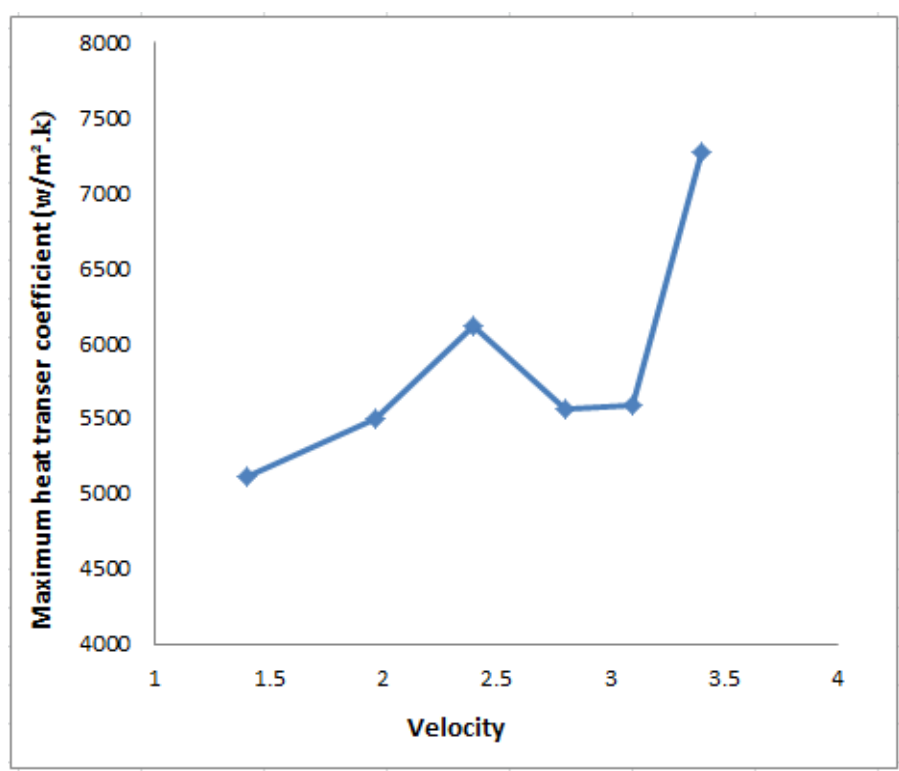

(B)

Figure (7 A and B): The relationship between collision velocities and maximum heat transfer coefficient for single drop and double drops.

In the figure, noticed that in the case of single drop the maximum heat transfer coefficient varies with the collision velocity and that the presence of a (hmax) is in the second spread of drop at time $0.5 \mathrm{~ms}$ by $\left(8980.745 \mathrm{w} / \mathrm{m}^{2} \mathrm{k}\right)$ with the maximum heat transfer coefficient occurs in the velocity of impact of $3.4 \mathrm{~m} / \mathrm{s}$ at $\mathrm{H}=60 \mathrm{~cm}$. While in the figure $(7-\mathrm{B})$, in the case of double drops, the maximum coefficient of heat transfer varies with the collision velocities and that the

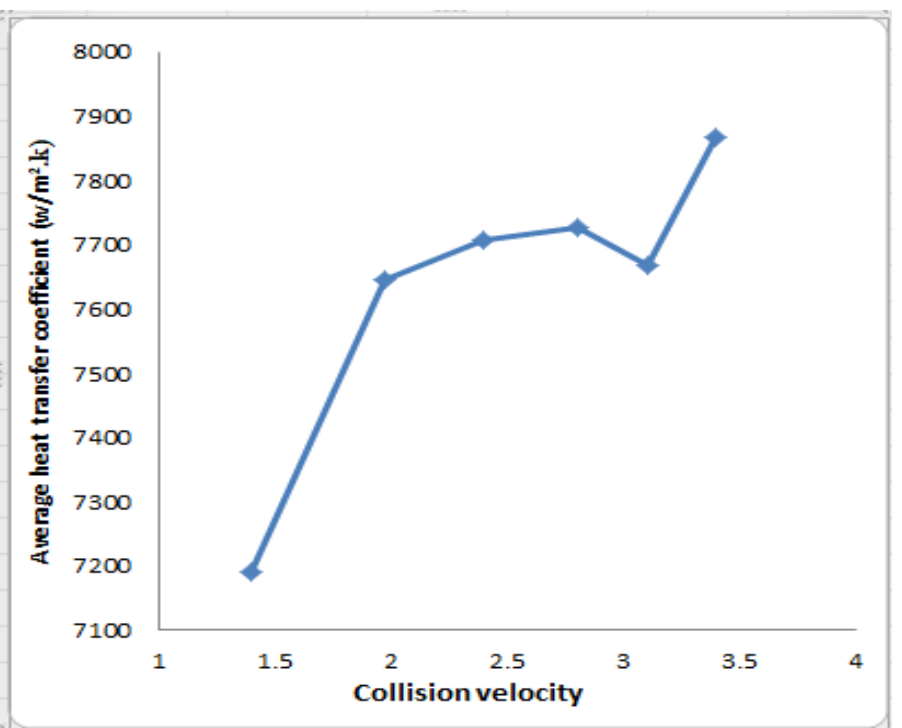

(A)

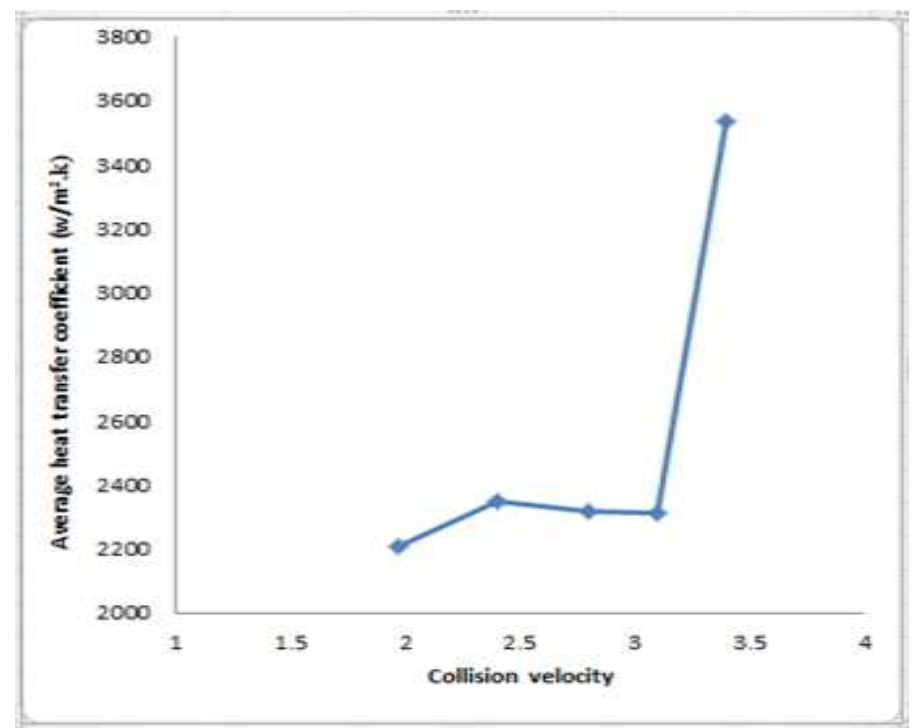

(B)

Single drop

Double drops

Figure (8 A and B): The relationship between collision velocities and average heat transfer coefficient in case of single drop and double drops. 
Notice in the figure that in the case of single drop, the average coefficient of heat transfer varies with the collision velocities, as well as the presence of a maximum (h average) presence is in the second spread of droplet at time $0.5 \mathrm{~ms}$ by $7867.45 \mathrm{w} / \mathrm{m}^{2} . \mathrm{k}$ in the case of single drop, while the maximum average heat transfer coefficient at time $(10 \mathrm{~ms})$ by $3534.245 \mathrm{w} / \mathrm{m}^{2} . \mathrm{k}$ in the case of double drops . For both cases these values are founded in the case of impact velocity of 3.4 $\mathrm{m} / \mathrm{s}$ and $\mathrm{H}=60 \mathrm{~cm}$. Results show that the flow characteristics for the double drops are similar to the single drop at small distances with smaller coverage areas during impingement with lower heat removal rates. As distances increase rebound and splash occurs leading to bigger coverage areas during impingement with relatively smaller heat coefficients compared to the single drop one.

\section{- Experimental Results:}

Experimental work was conducted in order to examine the effect of single drop of $3 \mathrm{~mm}$ diameter of water at temperature

\section{$\mathrm{H}=10 \mathrm{~cm}$}

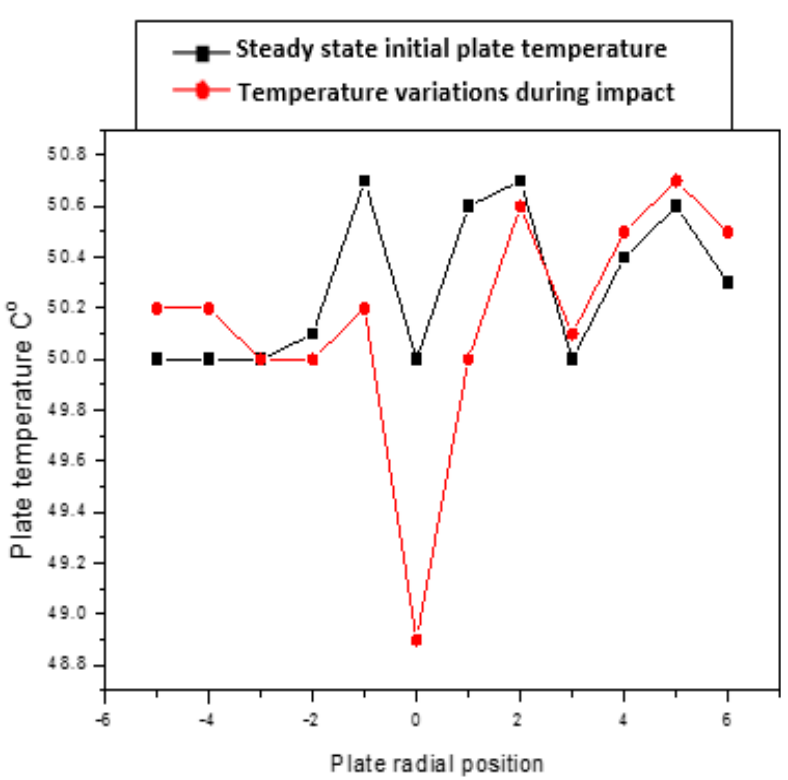

(A) of $25{ }^{\circ} \mathrm{C}$ impact on a heated plate made of stainless steel with thickness of $0.55 \mathrm{~mm}$ and at relatively higher constant temperature of $50{ }^{\circ} \mathrm{C}$. Both single drop and double drops are tested to measure the temperature reduction at the impact zone. This temperature reduction is then to be used to give an estimation of the heat transfer coefficients at the impingement zone. In case of single drop, which fall onto the center of heated plate, will leads to a reduction in temperature of the heated plate at the impact zone on the heated plate. The temperature distribution is measured on the plate at certain fixed points before and after the drop impact. Figure (9 A, B, $\mathrm{C}, \mathrm{D}, \mathrm{E}$ and F) reveal the distribution of temperature. In this figure, notice that the initial plate is fluctuated in its value due to the sensitive nature of the used thermocouples and the difficulty in reaching certain fixed temperature of the heated plate. The experimental test covered the impact drop height range tested in the numerical work mentioned earlier of $\mathrm{H}=$ (10-60) cm height range.

\section{$\mathrm{H}=20 \mathrm{~cm}$}

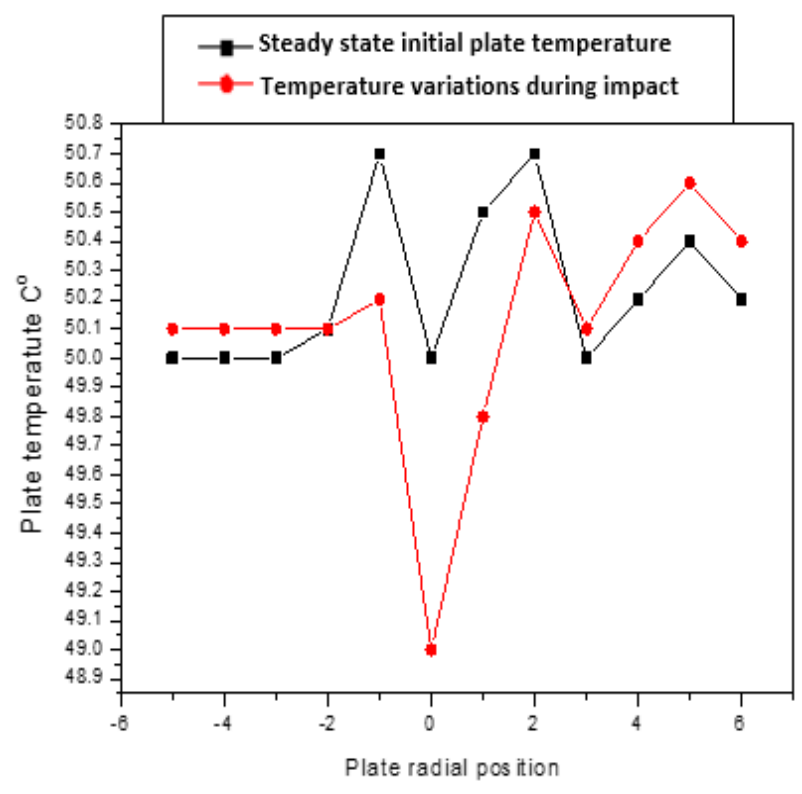

(B) 


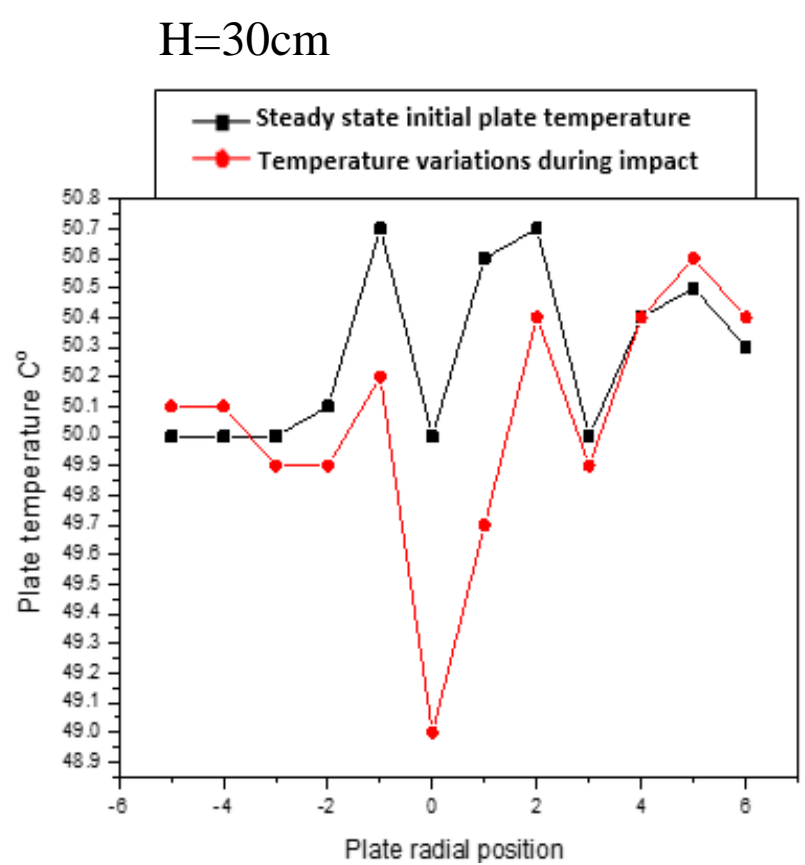

(C)

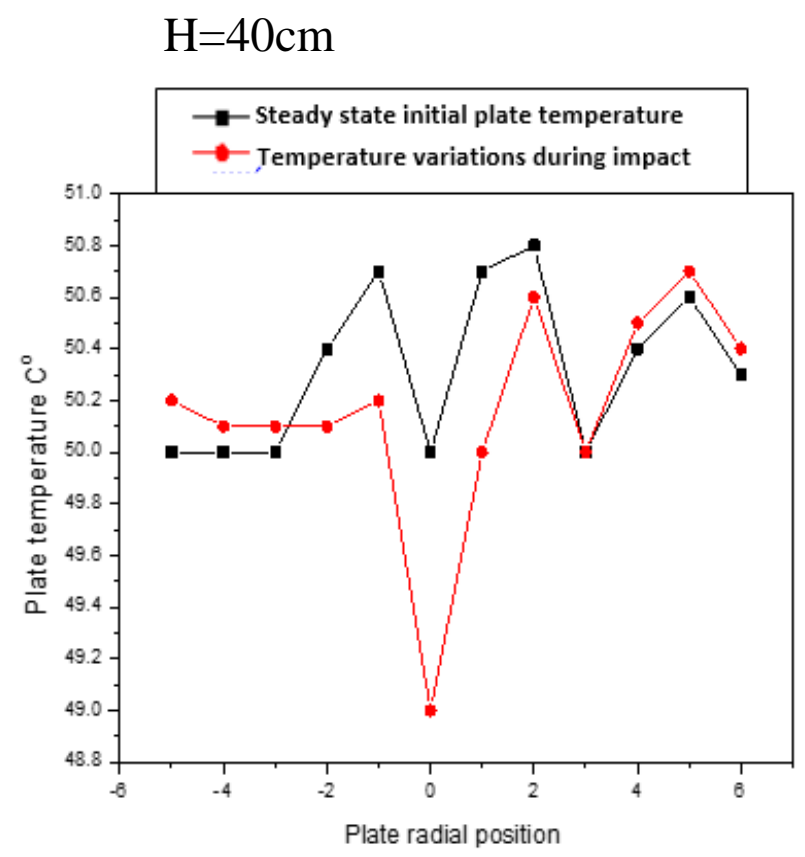

(D)

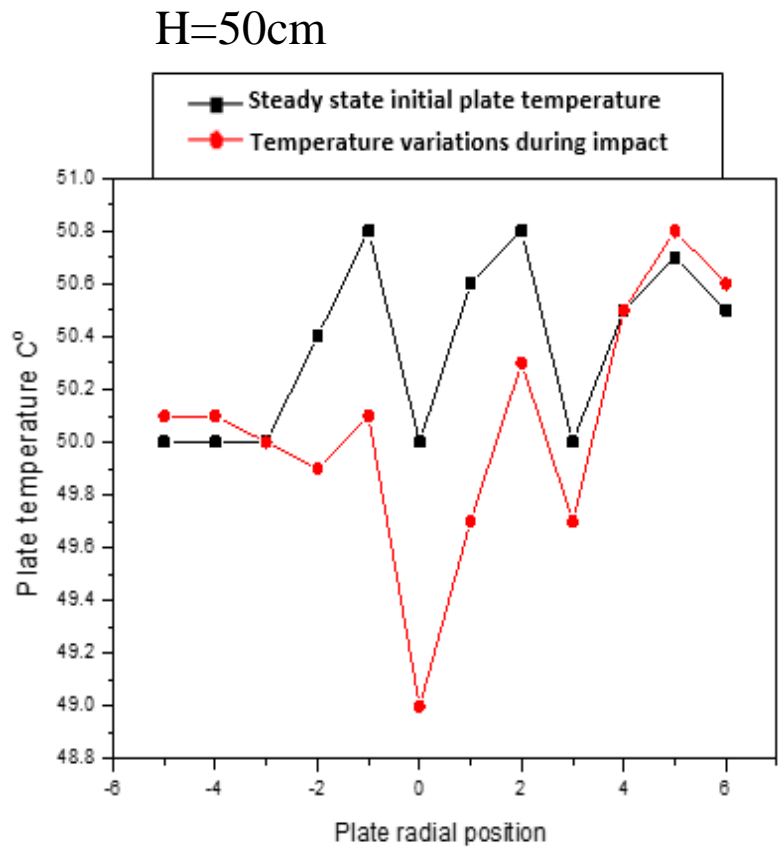

(E)

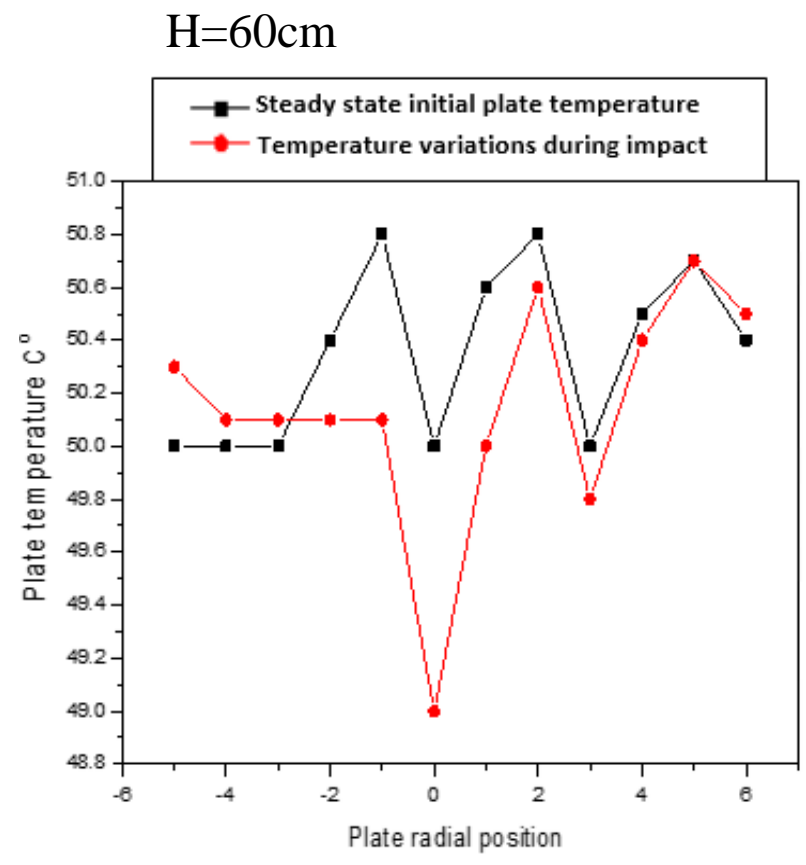

(F)

Figure (9 A, B, C, D, E, and F) single drop experimental reduction at the impact zone on the heated plate at different heights. $\mathrm{H}=10 \mathrm{~cm}, 20 \mathrm{~cm}, 30 \mathrm{~cm}, 40 \mathrm{~cm}, 50 \mathrm{~cm}$, and $60 \mathrm{~cm}$.

In this figure, when the temperature of the plate surface reaches $50{ }^{\circ} \mathrm{C}$ and the temperature of water drop is fixed at $25{ }^{\circ} \mathrm{C}$. As a single water drop ejected from the nozzle descending on the surface of the plate at the impingement zone, which leads to a decrease in the temperature at the effected center of the plate to $48.8^{\circ} \mathrm{C}$ for $\mathrm{H}=10 \mathrm{~cm}$ and to $49{ }^{\circ} \mathrm{C}$ for $\mathrm{H}=20 \mathrm{~cm}$ to $60 \mathrm{~cm}$. As shown in the figure, the initial temperature of the plate is not constant in the real measured case, but it is fluctuated from one point to other. This condition is due to difficulty in fixing the input power so that the temperature reaches the required temperature.

In the case of double drops, double water drops per second are ejected from the nozzle descending on the surface of the plate at the impingement zone. Temperatures are recorded by thermocouples and data logger before drop impact, when the drop is ejected and impact the plate at the required zone, the plate temperature start to decrease locally. At this time the temperature variations are recorded again. These variations 
"Single and Double Drop Impingement on a Heated Plate CFD and Experimental Investigation" are manifested in the figure (10A, B, C, D, E and F) for a height of $(10,20,30,40,50$ and 60$) \mathrm{cm}$, respectively.

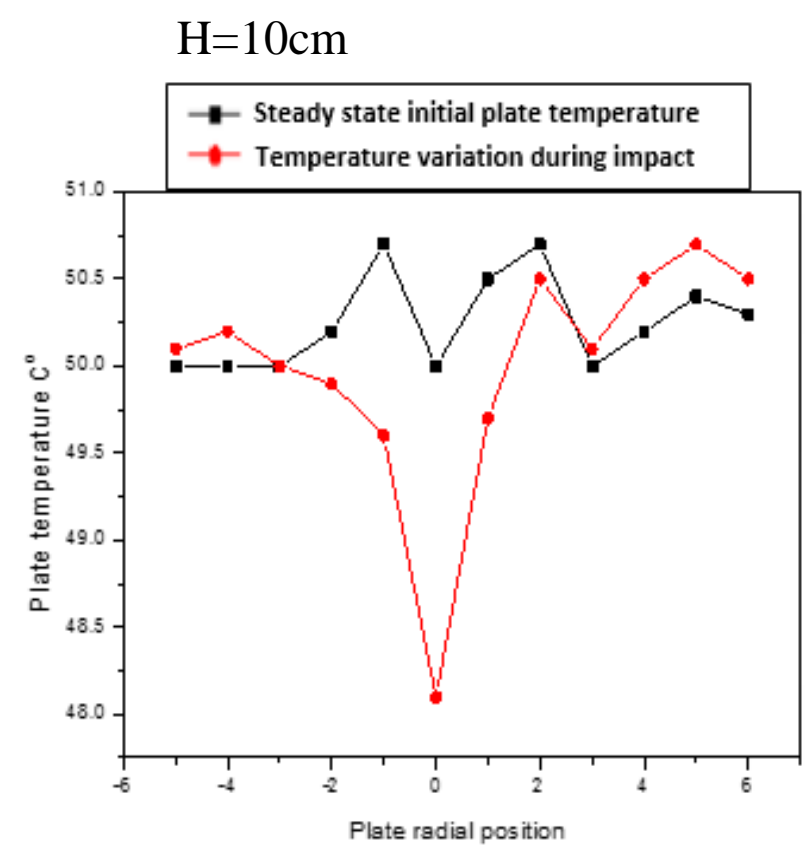

(A)

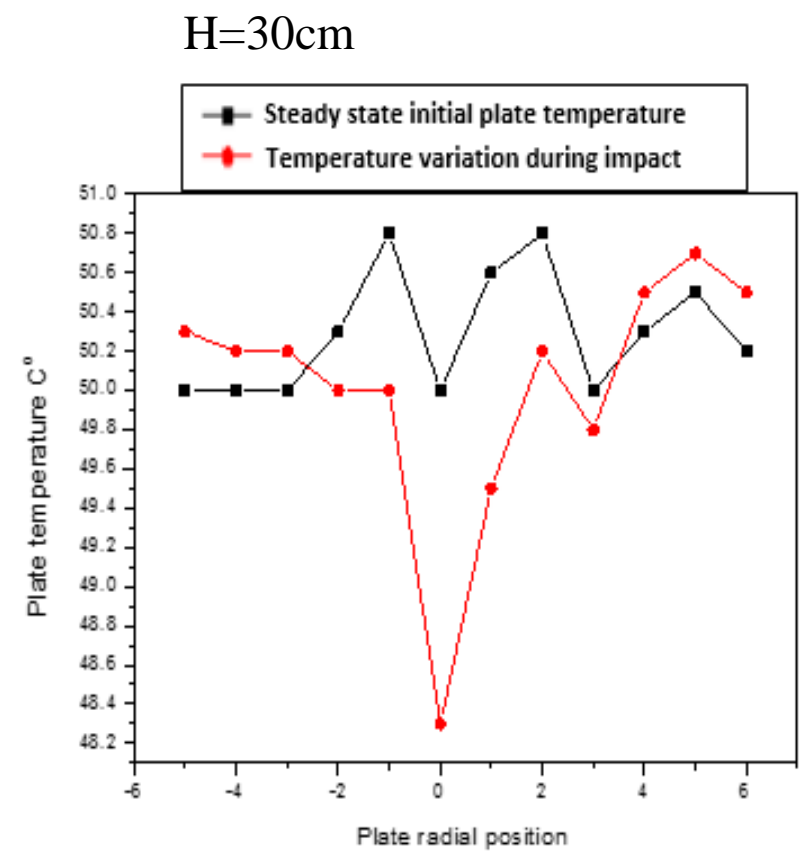

(C)

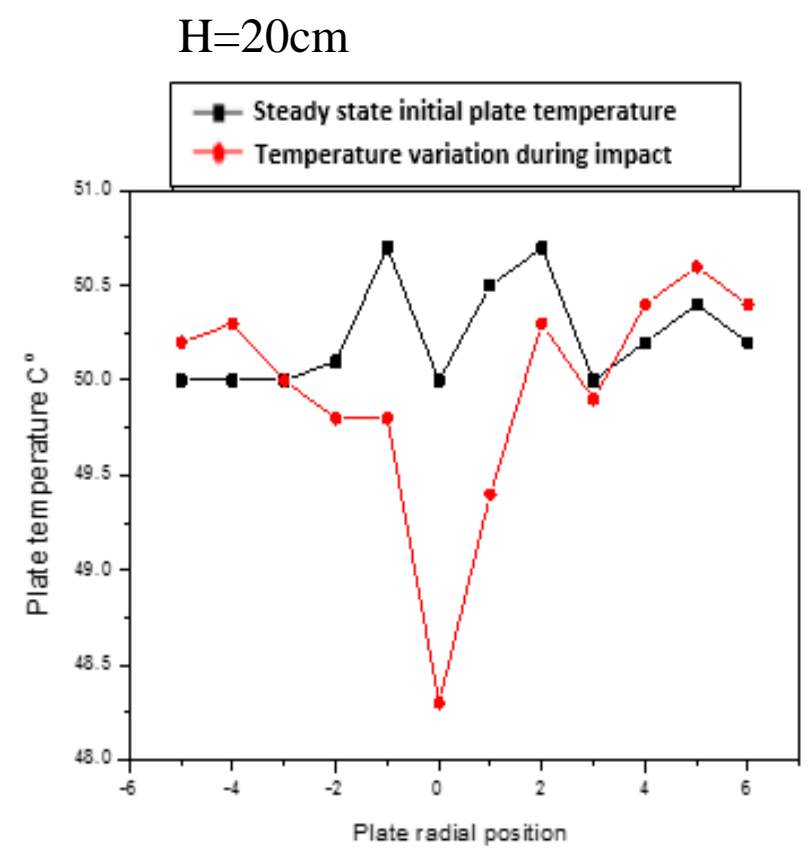

(B)

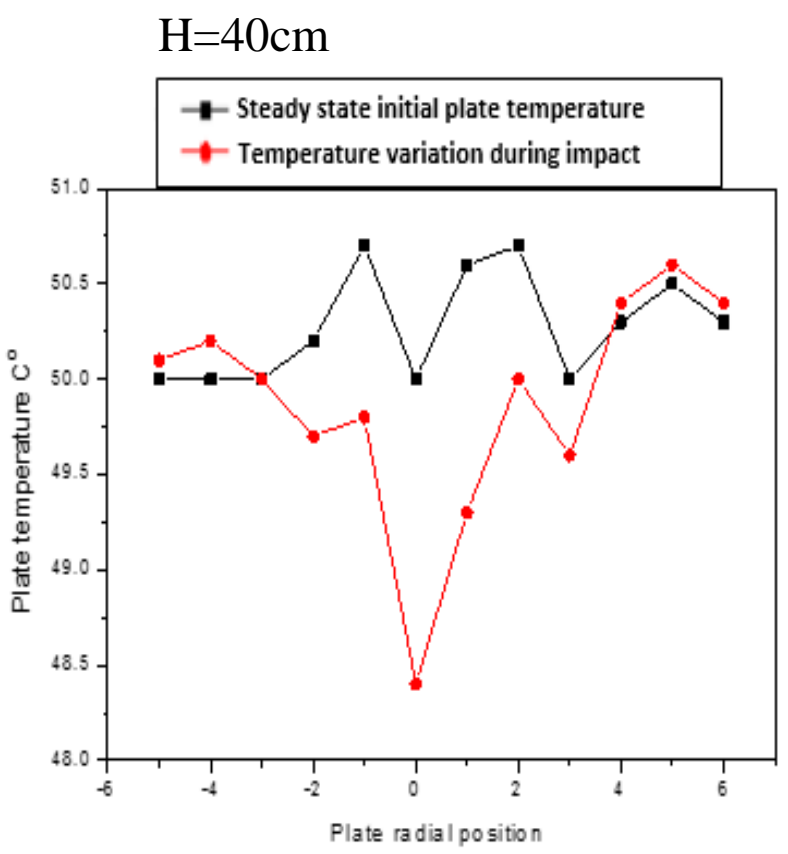

(D) 


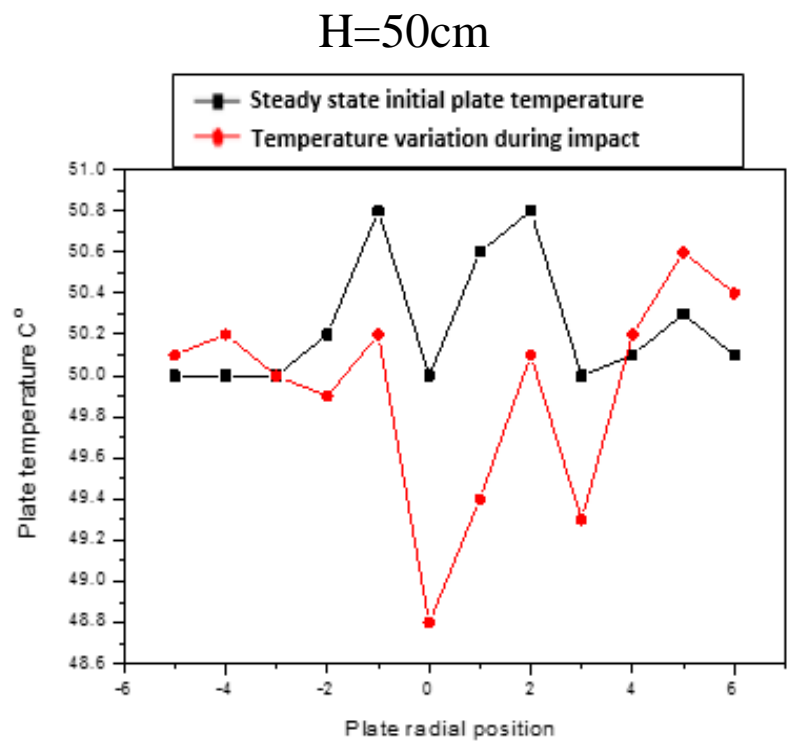

(E)

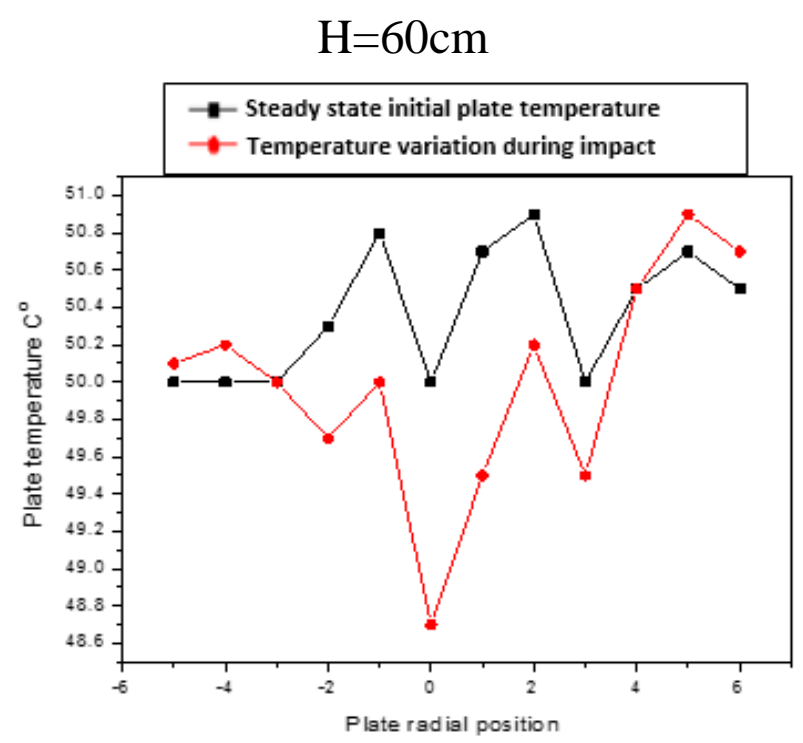

(F)

Figure (10 A, B, C, D, E and F): Double drops experimental temperature reduction at the impact zone on the heated plate at different heights. $\mathrm{H}=10 \mathrm{~cm}, 20 \mathrm{~cm}, 30 \mathrm{~cm}, 40 \mathrm{~cm}, 50 \mathrm{~cm}$ and $60 \mathrm{~cm}$.

In this figure, when the plate surface temperature reaches the limits of $50{ }^{\circ} \mathrm{C}$, it will fall off double droplets per second from the nozzle descending on the surface of the plate, which leads to a decrease in the temperature of the center of the plate after one second has passed to $48.1^{\circ} \mathrm{C}$ for $\mathrm{H}=10 \mathrm{~cm}$, to 48.3 ${ }^{\circ} \mathrm{C}$ for $\mathrm{H}=20 \mathrm{~cm}$ and $\mathrm{H}=30 \mathrm{~cm}$, to $48.4{ }^{\circ} \mathrm{C}$ for $\mathrm{H}=40 \mathrm{~cm}$, to $48.7{ }^{\circ} \mathrm{C}$ for $\mathrm{H}=50 \mathrm{~cm}$ and to $48.8{ }^{\circ} \mathrm{C}$ for $\mathrm{H}=60 \mathrm{~cm}$. The experimental monitoring of the drop impact on the plate declares that in single drop case the drop remains in the spreading mode in almost cases but it tends to

rebound and splash in double drops case specially at relatively high values of used heights.

The heat transfer coefficient was calculated using equation (18) at each point on the surface of the plate to calculate the average heat transfer coefficient in practice for $\mathrm{H}=(10-60) \mathrm{cm}$ range and to compare those results with the

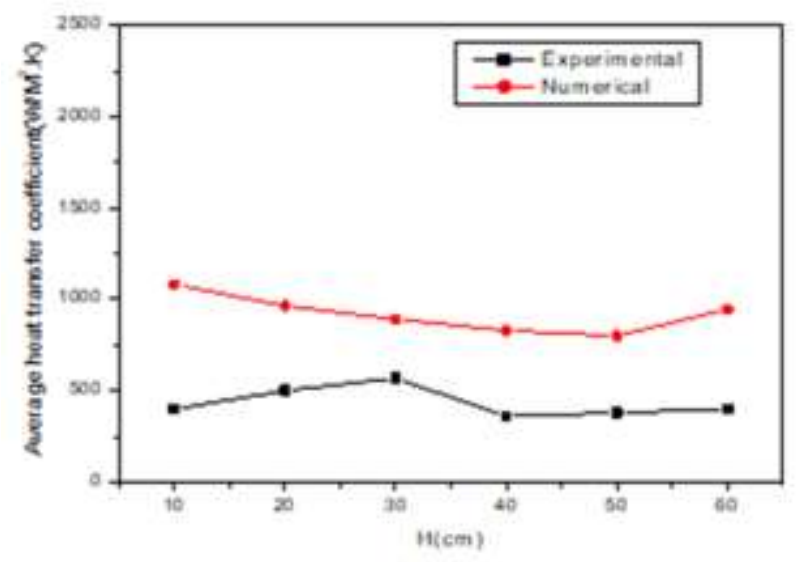

(A)

Single drop theoretical results in the case of single drop and double drops, as displayed in the figure (11 A and B).

In this figure, the single drop results for the average heat transfer coefficients are calculated using the equation (18) with its different two terms, are noticed to be almost constant (i.e., the convective and heat generation term). The third term which represents the transient temperature variation plays the biggest role in finding the average heat coefficient. The time used for calculating the transient term depends on the time elapsed till the drop starts to reaccumulate (i.e., when the deformation of the drop ends). This time is founded from the numerical results because it cannot be found experimentally. Also, this time elapsed is found numerically to be variable with drop to plate heights. The values of have shown error of $30 \%$, while that for double drops case given a lower error of a value $5 \%$, as shown in figure based on the numerical results.

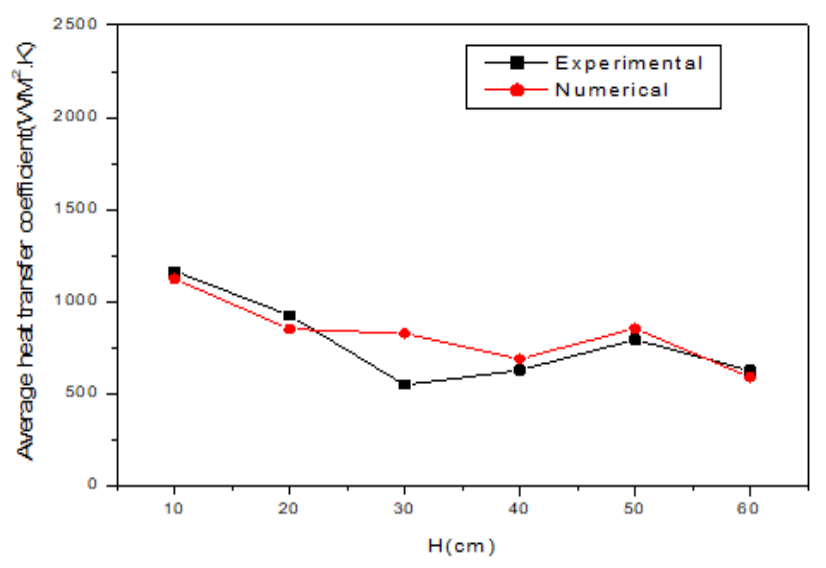

(B)

Double drop

Figure (11 A and B): Variation of conjugated heat transfer coefficient in experimental and numerical for both single drop and double drops cases. 


\section{CONCLUSION}

The present work carried out a CFD analysis for single and double cold water drops on a heated plate in addition to an experimental investigation during a test rig built for the purpose. The following is the main conclusions

1-The volume of fluid (VOF) model is an efficient one to simulate the flow behavior and heat removal from a heated surface.

2-The single water drop condition gives a symmetrical distribution of temperature and heat coefficient with uniform higher values of heat transfer coefficient relative to the double drop impingement case for the tested drop to plate distances of (10-60) cm values.

3-The spread factor increase with the increase of drop to plate distances.

4-The heat transfer coefficients is estimated experimentally using a heat balance method and the CFD spreading time. The double drop average heat transfer coefficients values are with lower error of 5 only relative to the single drop values.

\section{REFRENCES}

1. C. Camci and F. Herr, "Forced convection heat transfer enhancement using a self-oscillating impinging planar jet," J. Heat Transfer, 2002, doi: 10.1115/1.1471521.

2. D. Li, X. Duan, Z. Zheng, and Y. Liu, "Dynamics and heat transfer of a hollow droplet impact on a wetted solid surface," Int. J. Heat Mass Transf., 2018 ,

doi: 10.1016/j.ijheatmasstransfer.2018.02.017.

3. A. L. Yarin, "Drop impact dynamics: Splashing, spreading, receding, bouncing..," Annual Review of Fluid Mechanics. 2006, doi: 10.1146/annurev.fluid.38.050304.092144.

4. R. Rioboo, C. Tropea, and M. Marengo, "Outcomes from a drop impact on solid surfaces," At. Sprays, 2001, doi: 10.1615/atomizspr.v11.i2.40.

5. J. Li, Q. Han, Y. Zhao, and X. Yuan, "Deposition process of droplets impacting on a horizontal surface," 2012,

doi:10.4028/www.scientific.net/AMR.354-355.579.

6. K. Fujisawa, T. Yamagata, and N. Fujisawa, "Damping effect on impact pressure from liquid droplet impingement on wet wall," Ann. Nucl. Energy, 2018, doi: 10.1016/j.anucene.2018.07.008.

7. K. K. Haller, Y. Ventikos, D. Poulikakos, and P. Monkewitz, "Computational study of high-speed liquid droplet impact," J. Appl. Phys., 2002, doi: 10.1063/1.1495533.

8. C. Hao et al., "Superhydrophobic-like tunable droplet bouncing on slippery liquid interfaces," Nat. Commun., 2015, doi: 10.1038/ncomms8986.

9. I. V. Roisman and C. Tropea, "Fluctuating flow in a liquid layer and secondary spray created by an impacting spray," Int. J. Multiph. Flow, 2005, doi: 10.1016/j.ijmultiphaseflow.2004.11.001.

10. Ansys Inc.2017 ANSYS FLUENT user guide (Release 19). Multiphase Flow: Ansys Inc

11. C. Hirsch, "Numerical Computation of Internal and External Flows": The Fundamentals of Computational Fluid Dynamics. 2007.

12. Zikanov O 2010 Essential Computational Fluid Dynamics Wiley.

13. Ansys Inc.2017 ANSYS FLUENT theory guide (Release19). Multiphase Flows. : Ansys Inc. 